\title{
O AUMENTO DAS "FAKE NEWS" DURANTE A PROPAGANDA ELEITORAL E SUA POSSÍVEL INFLUÊNCIA NO RESULTADO DO PLEITO
}

\author{
Lucas Gonçalves da Silva ${ }^{1}$ \\ Elaine Celina Afra da Silva Santos ${ }^{2}$
}

\section{RESUMO}

O presente artigo procura analisar, através da noção de sociedade da informação como decorrência da pós-modernidade, o advento das tecnologias como ferramentas importantes na divulgação de notícias e também no incremento da propaganda eleitoral. Através do estudo das redes sociais, internet e outros aplicativos, depreende-se que, na pós-modernidade, estar conectado é, antes de tudo, condição básica para interações sociais, o que poderá abrir espaços para divulgação de notícias falsas, as chamadas "fake news". Estas notícias, com o nítido intuito de confundir seus destinatários e influenciar no resultado do pleito eleitoral, serão analisadas sob o viés ideológico que podem representar e com o objetivo final do estudo de responder se efetivamente, o aumento da disseminação de notícias desta natureza pode alterar o resultado de uma eleição. Foi utilizado o método hipotético dedutivo, pesquisa bibliográfica e documental, e objetivo exploratório.

Palavras-chave: Eleição, Fake news, Propaganda eleitoral, Redes sociais, Sociedade da informação.

\section{THE INCREASE OF FAKE NEWS DURING ELECTORAL PROPAGANDA AND ITS POSSIBLE INFLUENCE IN THE PLEIT RESULT}

\begin{abstract}
This article seeks to analyze, through the notion of information society as a result of postmodernity, the advent of technologies as important tools in the dissemination of news and also in the increase of electoral propaganda. Through the study of social networks, internet and other applications, it can be seen that, in postmodernity, being connected is, first and foremost, a basic condition for social interactions, which may open spaces for the dissemination of false news, fake news ". This news, with the clear intention of confusing its recipients and influencing the outcome of the electoral process, will be analyzed under the ideological bias they can represent and with the final objective of the study to answer if effectively, the increase in the dissemination of news of this nature can alter the result of an
\end{abstract}

\footnotetext{
${ }^{1}$ Pós-doutor em Direito pela Università Degli Studi G. dAnnunzio (Italia) e pela Universidade Federal da Bahia. Doutor e Mestre em Direito do Estado, na sub-área de Direito Constitucional, pela Pontifícia Universidade Católica de São Paulo-PUC/SP. Professor Associado da Graduação em Direito e do Programa de Mestrado em Direito na Universidade Federal de Sergipe-UFS. Consultor da Câmara de Assessoramento da FAPITEC/SE. Consultor da Coordenação de Aperfeiçoamento de Pessoal de Nível Superior - Capes. Vice-Presidente do Conselho Nacional de de Pesquisa e Pós-graduação em Direito - CONPEDI .Endereço Eletrônico: lucasgs@uol.com.br;

${ }^{2}$ Magistrada Estadual, em exercício no Tribunal de Justiça de Sergipe. Pós Graduada em Ciências Criminais pelo Centro Universitário Jorge Amado, UNIJORGE; Pós Graduada em Direito Público pela Universidade Salvador, UNIFACS; Mestranda em Direito na Universidade Federal de Sergipe. Endereço Eletrônico: elaineafra@ hotmail.com.
} 
election. The hypothetical deductive method, bibliographical and documentary research, and exploratory objective were used.

Key-words: Election, Fake News, Electoral propaganda, Social networks, Information Society.

\section{INTRODUÇÃO}

As transformações sociais pelas quais a humanidade passou no último século trouxeram consigo a problematização acerca das formas de comunicação utilizadas, pois estas adquiriram modalidades até então desconhecidas e que solaparam de vez os antigos mecanismos de troca de informações. O homem passou a se comunicar de forma mais simples e mais rápida, o que provocou uma revolução na era da comunicação, permitindo que um número bem mais expressivo de pessoas tivesse acesso às notícias até então restritas a uma parte delas.

A transição da sociedade agrícola para a sociedade industrial talvez não tenha causado tanto avanço como a transição, ainda em andamento, da sociedade capitalista moderna para a pós-moderna ou sociedade da informação. A diferença entre a Sociedade Industrial e da Sociedade da Informação são vistas pelas seguintes características: a Sociedade Industrial tem em seu núcleo a máquina a vapor, cuja função básica é a substituição do trabalho físico e a produção de bens e serviços. Já a Sociedade da Informação tem como núcleo o computador e sua função básica é substituir e amplificar o trabalho mental do indivíduo, resultando no que se chama de criação da tecnologia e do conhecimento.

Para se estabelecer nitidamente esta diferença, serão analisados em um primeiro momento a sociedade da informação, seu surgimento, características e profundas mudanças advindas com ela. A partir disso, será questionado até que ponto o aumento da disseminação de notícias falsas pode ou não modificar o resultado de uma eleição. Ao longo da explanação, percebe-se o importante papel das novas tecnologias como ferramentas essenciais na divulgação de notícias e também no incremento da propaganda eleitoral. Nesse contexto, as redes sociais, internet e outros aplicativos são, antes de tudo, condição básica para interações sociais, o que poderá abrir espaços para divulgação de notícias falsas, as chamadas "fake news". Por fim, defende-se que estas notícias, com o nítido intuito de confundir seus destinatários e influenciar no resultado do pleito eleitoral, serão analisadas sob o viés 
ideológico que podem representar e com o objetivo final do estudo de responder se efetivamente, o aumento da disseminação de notícias desta natureza pode alterar o resultado de uma eleição.

Quanto à metodologia aplicada foi utilizado o método hipotético dedutivo, com aplicação da técnica da pesquisa bibliográfica e documental que serviram de premissas teóricas para a grande maioria das considerações feitas ao longo do artigo, bem como objetivo exploratório.

\section{SOCIEDADE DA INFORMAÇÃO}

Esse termo Sociedade da Informação surgiu “...pela voz do presidente da Comissão Européia. Jaques Delors, por ocasião do Conselho Europeu (1993), ao lançar pela primeira vez a ideia de infraestruturas da informação" (PRATES, 2015. Pg. 25). Ou seja, desde a década de 90 o termo vem sendo cunhado para designar a era da tecnologia, onde a informação assume novo patamar ao ser disseminada de forma mais rápida e efetiva. Ainda sobre esse tema diz o mencionado Autor:

“ O termo faz referência a um modo de desenvolvimento socioeconômico em que a aquisição, armazenamento, processamento, valorização, transmissão, distribuição e disseminação de informação, conducente à criação de conhecimento e à satisfação das necessidades dos cidadãos e das empresas, desempenham um papel central na atividade econômica, na criação de riqueza, na definição de qualidade de vida dos cidadãos e de suas práticas culturais".

A informação portanto, na sociedade pós-moderna, caracterizada pelo monopólio da tecnologia, faz antever os benefícios e desafios que apontam na direção de um caminho sem volta, onde o cidadão até então restrito a um número tal de conhecimentos, passou a ser bombardeado por notícias e ainda mais, passou a ser protagonista da sua disseminação, à medida que pode, a partir do advento das mencionadas tecnologias, promover a inserção maciça de dados na rede e assim transmiti-las a um sem número de usuários. 
Nesta seara, já podemos perceber que cada ser humano munido de um computador ou equivalente tecnológico, poderá se fazer ouvir numa dimensão jamais dantes imaginada, divulgando sua opinião, suas convicções ou até mesmo forjando informações de caráter ideológico, visando por exemplo, alterar as intenções de voto numa eleição, mas sobre isso falaremos adiante no texto.

Toda tecnologia, que ainda está em pleno desenvolvimento, fez com que o Direito voltasse seus olhos aos novos modos de relações/interações sociais, tendo em vista que, a exemplo da informação, que passou a ser amplamente disseminada através de dispositivos e aplicativos novos, outras interfaces estarão suscetíveis de mudança.

Não é a toa que vários órgãos de caráter internacional buscam regulamentar o uso das redes, a exemplo da Agência Europeia para Segurança das Redes e da Informação criada pela Comunidade Europeia, pelo Regulamento n. 167 n. 460/2004/CE em 10 de março de 2004, visando um mínimo de segurança jurídica e uniformização dos procedimentos e regras ligados aos usuários das redes, conforme dito por BRITO, 2014, pág. 26, algo extremamente difícil em se tratando de rede mundial de computadores.

Fato é que não se pode mais tratar institutos jurídicos tradicionais da mesma forma que eram tratados quando do advento do Estado Moderno, pois este sofreu e ainda sofre mudanças decorrentes da pós-modernidade e do avanço da tecnologia como dito anteriormente. A virtualização do mundo real trouxe consigo a necessidade de atualizar princípios e institutos jurídicos garantidos pelas Constituições.

\section{LIBERDADE DE EXPRESSÃO E LIMITES}

Podemos dizer que a liberdade de expressão é um daqueles princípios que precisam ser revisitados e portanto, reinterpretados pelo direito diante da era pós-moderna, altamente caracterizada pela utilização das diversas tecnologias como forma de comunicação. Assim, a liberdade de se expressar e se comunicar assumiu um novo status na era da informação, fazendo jus a análise de como esta liberdade vem sendo elaborada.

O fato de estarmos diante de uma sociedade informatizada nos diz muito sobre como a comunicação passou a ser realizada. Antes, utilizávamos o telefone com fio, as cartas e o fax como meio de comunicação e troca de mensagens. A partir do advento do computador estas 
formas de comunicação foram sendo deixadas para trás para dar lugar aos inúmeros 'gadgets' ${ }^{3}$ responsáveis pelo novo modo de se comunicar. Assim, o advento dos celulares deu início a nova era da comunicação digital.

Isto fez com que as mensagens pudessem ser transmitidas com maior celeridade e ainda pudessem ser compartilhadas com inúmeros outros usuários, dando vazão assim a opinões, pensamentos e idéias de uma maneira nunca antes vista. Segundo PRATRES, 2018, pg 31: “A plataforma da internet é organizada na inovação do bem comum. Basta conectar-se a ela para acrescentar seus dados, favorecendo o crescimento individual, democratizando e redistribuindo o conhecimento das autoridades centrais para os indivíduos".

Nesse sentido, podemos dizer que houve uma ampliação da liberdade de expressão, pois as plataformas digitais permitiram que mais pessoas pudessem divulgar suas idéias e opiniões, ampliando também o público destinatário das mesmas. A facilidade com que a informação é repassada entretanto, faz com que em sua grande maioria não sejam checadas as suas origens ou veracidade, o que dá margem às notícias falsas ou fake news que trataremos mais aditante.

Fato é que, se de um lado temos a garantia constitucional à liberdade de expressão, o que significa o direito de se expressar livremente, de outro temos o questionamento acerca da possibilidade de inserir neste direito a disseminação de notícias falsas. Este tema que ainda vem sendo debatido, deverá levar em consideração algumas premissas. A primeira delas é que a liberdade de expressão é fundamento essencial de uma sociedade democrática e uma das condições básicas para o progresso dessa sociedade (BUCCI, 2018, p. 181) e para realização e desenvolvimento individual. A outra, consiste em reconhecer limites razoáveis ao exercício deste direito, sobretudo no que tange à vida privada, direitos à imagem, intimidade, honra e afins.

A liberdade de expressão como garantia decorrente de um Estado Democrático de direito, consagra a ideia e tutela a diversidade de ideias e opiniões, devendo ser permitida de forma ampla e irrestrita, tanto que é vedado pelo texto constitucional brasileiro a censura prévia, como previsto no artigo 5, inciso IX. A liberdade de pensamento implica a liberdade

\footnotetext{
${ }^{3}$ Gadget é uma palavra estrangeira muito presente no vocabulário do brasileiro que vem sendo usada para designar dispositivos eletrônicos portáteis de maneira genérica. Smartphones, tablets, notebooks, HDs externos, carregadores portáteis: todos eles fazem parte do universo definido por esse vocábulo de (possível) origem francesa. Extraído de <https://www.techtudo.com.br/noticias/2018/05/o-que-e-gadget-descubra-o-significadotecnologico-da-palavra.ghtml > Acesso em 11/04/19 as 14:31.
} 
de manifestação do pensamento, por qualquer forma ou veículo, incluindo-se na era da informação a transmissão através de aplicativos e redes sociais.

Nesse sentido é que entendo, sob pena de haver limitações ao exercício deste direito fundamental, estaria permitida a divulgação de notícias sem a devida checagem acerca de sua veracidade/origem ou até mesmo com o intuito de provocar a dúvida, pois estariam as mesmas inseridas neste rol de manifestação do pensamento, o qual não deve sofrer limitações. A única ressalva que se poderia admitir são manifestações, divulgação de notícias falsas que viessem a atingir o direito à intimidade, vida privada, honra e imagem da pessoa, o que, no caso dos candidatos numa eleição, por se tratarem de pessoas públicas, sofreriam um filtro no que tange ao tipo de informação remeter-se à pessoa do candidato, o que estaria permitido, ou à pessoa privada, o que estaria proibido.

A verdade é que o entendimento que as cortes superiores têm da matéria é no sentido de dar ampla interpretação à liberdade de expressão e restringir a mesma no que tange aos seus limites. Segundo BUCCI, 2018, pág. 184:

“Como vimos, o direito a liberdade de expressão não é absoluto e pode, portanto, sofrer restrições. O direito a liberdade de expressão é interpretado pelas cortes de forma ampla, e as restrições a esse direito, restritivamente. Isso para garantir, como vimos acima, o debate necessário em uma sociedade democrática.

A existência de outros direitos, como, por exemplo, à intimidade, à reputação, à honra, à imagem, à privacidade, à segurança nacional e à moral pública permitiriam num primeiro momento, restrições ao exercício da liberdade de expressão. As cortes reconhecem a necessidade de uma harmonização entre esses direitos e a liberdade de expressão"

A liberdade de expressão tem primazia quando colocada em confronto com direitos de outras espécies, pois é pilar do Estado Democrático de Direito que garante ao seu cidadão a possibilidade de expor sua ideias e manifestar seus pensamentos de forma integral, inclusive aquelas que chocam ou perturbam, como asseverado pela Autora supra citada ao dizer: 
“...Assim, a liberdade de expressão protege todas as ideias e informações, inofensivas ou indiferentes, mas também as que ofendem, chocam ou perturbam. Essa proteção é necessária porque, para que uma sociedade democrática floresça, é preciso permitir que se difundam ideias que não são homogêneas, as críticas e o debate público."

Podemos dizer portanto, que a disseminação de notícias sabidamente falsas estariam no rol das expressões de pensamento caracterizadas por manifestação de opinião ou pensamento, de modo que não se poderá impor limites à sua divulgação, salvo a comprovação de que as mesmas estariam atingindo a honra, imagem, intimidade, privacidade, do interessado.

\section{O ADVENTO DAS FAKE NEWS NAS ELEIÇÕES}

A corrida presidencial sempre foi tema que despertou muito interesse na mídia de um modo geral e na própria população diretamente interessada no resultado do pleito. E tal não poderia ser diferente, tendo em vista que a eleição do Chefe do Poder Executivo pode acarretar mudança em todo cenário político de um país, tendo em vista as opções políticoadministrativas adotadas e todo consectário econômico que passará a vigorar com um novo governo.

Visível portanto, o interesse que desperta a disseminação de notícias que visem desqualificar o candidato adversário ou seu programa de governo. Num tempo marcado pela informação compartilhada de modo mais célere e onde a repercussão de uma notícia falsa pode acarretar a 'desgraça' de uma campanha eleitoral, nunca foi tão perceptível o aumento das chamadas "fake news" com aquele intuito.

O site G1 pertencente ao grupo O Globo, assim como tantos outros veículos de comunicação, chegaram a criar setores específicos em suas redações, visando aferir a veracidade das informações disseminadas na rede, com o objetivo de esclarecer a população e assim, transmitir notícia teoricamente mais fidedignas. 
No caso específico aqui apontado, o site G1.com.br criou em 30/07/2011 um serviço de checagem de conteúdos suspeitos, onde objetiva "checar as mensagens que causam desconfiança e esclarecer o que é real e o que é falso. Apuração será feita em conjunto com jornalistas do G1, O Globo, Extra, Época, Valor, CBN, Globonews e TV Globo. Discursos de políticos também serão conferidos..."4

A chamada sociedade em rede, expressão cunhada por CASTELLS, 2013, fez com que o simples cidadão, antes mero receptor de informações acerca do seu candidato/partido, passasse a ser emissor/divulgador de uma série de informações altamente compartilháveis a respeito do mesmo, facilitando assim a disseminação de conteúdos altamente contamináveis não só pela ideologia impregnada mas pela própria falibilidade de sua verossimilhança. Esta disseminação acarreta a formação de conteúdos questionáveis quanto a sua veracidade, mas com alto poder de persuasão social, questão altamente interessante aos candidatos que concorrem a uma vaga na disputa eleitoral.

Assim, percebe-se que a disseminação de notícias falsas possui dois efeitos: causar descrédito àquele diretamente prejudicado com a notícia e consequentemente o veículo que o disseminou; e influenciar o pensamento/ideologia daquele que consumiu a falsa notícia.

No que tange ao primeiro efeito da disseminação de notícias falsas, ou seja, causar descrédito ao objeto da notícia, percebe-se uma tentativa de arrefecer o sucesso do referido objeto (que no caso do pleito eleitoral pode ser uma pessoa que é o candidato) ou sua influência diante dos demais e assim, assumir a posição de garante da verdade, pois haveria nesta atitude algo de altruísta. Neste quesito, não só as empresas jornalísticas, de gestão de carreiras e grandes conglomerados empresariais, mas também os algoritmos teriam a intenção de faltar com a verdade buscando deliberadamente o fracasso do objeto da notícia. Nesse sentido:

"Que fique bem claro: isso não é um defeito de projeto. É aquilo que
os algoritmos se destinam a fazer: conectarmos com as coisas que
gostamos ou podemos vir a gostar. Trata-se de algo bastante
responsável ao gosto pessoal e - até agora - bastante cedo à
veracidade. A web é o vetor definitivo da pós verdade, exatamente

\footnotetext{
${ }^{4}$ Informação coletada em 15 de outubro de 2018 as 22:56 em www.g1.com.br.
} 
porque é indiferente a mentira, à honestidade e à diferença entre os dois" ( D'ANCONA, 2018).

Os veículos de comunicação atentaram ainda para o fato de que, não se esclarecendo a veracidade da informação falsa na origem e posteriormente descoberta, teriam comprometidas não só a credibilidade da própria instituição ao difundir a notícia, como eventualmente deixaria alastrar ideologia contrária a seus interesses. Foi assim que o tema fake news passou a ter importância necessária a ponto de merecer, no caso do jornal virtual antes mencionado, uma seção apenas visando o esclarecimento de notícias compartilhadas.

E não é outro senão este, o papel exercido por estes jornalistas envolvidos na temática de combate às falsas notícias, as quais, em se tratando de pleito eleitoral, possuem o condão de alterar o resultado das eleições, sobretudo diante de um cenário cada vez mais frequente onde grande parte da população se encontra indecisa.

O descrédito causado àquele que é objeto da notícia falsa poderá acarretar danos à sua imagem e à sua moral, o que dificilmente poderá ser restaurado tal como antes. É que, ao ter seu nome envolvido em uma notícia falsa, o atingido, dada à rapidez de disseminação da mesma, não terá o mesmo espaço e rapidez para desfazê-la ${ }^{5}$, o que por si só o prejudica. Ou seja, a depender da gravidade da imputação feita, nunca se poderá estabelecer o status quo ante da pessoa.

O mesmo se diga em relação ao veículo difusor da notícia e que não teve o cuidado de checar a informação divulgada, a qual, uma vez desmentida, transmitirá ao seu público a impressão de que suas fontes não são fidedignas e portanto, não possuem credibilidade enquanto veículo jornalístico, o que por conseguinte acarretará, a longo prazo, a ruína daquele.

Em se tratando de campanha eleitoral, esta consequência poderá ser ainda mais nefasta e se refletir nos votos das urnas. É o que se pode perceber na campanha presidencial de 2018, em que, ao lado das propostas emanadas dos candidatos ao segundo turno, percebeu-se o AUMENTO do número de notícias falsas veiculadas através das redes sociais.

\footnotetext{
${ }^{5}$ As notícias falsas se espalham $70 \%$ mais rápido que as verdadeiras e alcançam muito mais gente. A conclusão é do maior estudo já realizado sobre a disseminação de notícias falsas na internet, realizado por cientistas do Instituto de Tecnologia de Massachusetts (MIT, na sigla em inglês), dos Estados Unidos. O novo estudo foi publicado nesta quinta-feira, $(8 / 3)$, na revista Science. Informação coletada no site: https://www.correiobraziliense.com.br/app/noticia/tecnologia/2018/03/08/interna_tecnologia,664835/fake-newsse-espalham-70-mais-rapido-que-noticias-verdadeiras.shtml em 15/10/2018 as 23:23.
} 
Uma das explicações para este fato, segundo estudo publicado na revista Science em $08 / 03 / 2018^{6}$, é que as notícias falsas se espalham $70 \%$ mais rápido que as verdadeiras e alcançam muito mais gente segundo os cientistas do MIT (Instituto de Tecnologia de Massachusetts ), numa clara demonstração da necessidade de se verificar a origem e veracidade dos fatos que estão sendo divulgados nas redes e nos veículos de comunicação. Por isso que o reestabelecimento da verdade tem o difícil papel de recolocar o atingido no estado que se encontrava anteriormente à notícia, o que sabidamente é impossível.

Outro fato importante para o crescimento das fake news, segundo André Miceli, professor e coordenador do MBA em Marketing Digital da Fundação Getúlio Vargas (FGV) ${ }^{7}$, é o advento das redes sociais como o aplicativo Whatsapp que permitem a troca de informações em tempo real, para um grupo inicialmente restrito, mas que vai se espraiando, o que denota a importância desses influenciadores, contratados ou voluntários, que cresceu de modo acentuado em 2018, ante a queda do peso da comunicação direta de políticos com o eleitorado via horário eleitoral e campanha nas ruas.

A facilidade da comunicação advinda dos meios eletrônicos a disposição dos usuários, reflete a rapidez de disseminação de conteúdo, o qual mesmo que compartilhado com as pessoas mais próximas, com o efeito cascata, possuem o condão de disseminar para um número bastante significativo de pessoas a informação. Aliás, é o que mostra o estudo já aqui mencionado na Revista Science, o qual demonstrou ainda que, enquanto uma notícia verdadeira atinge cerca de mil pessoas, uma notícia falsa atinge de mil a cem mil pessoas ${ }^{8}$, restando claro o alto poder de disseminação das notícias falsas.

Baseada nessa constatação, a maioria dos veículos de comunicação, sobretudo com sede no mundo virtual mas não só nele, criou um setor com o objetivo específico de verificar a veracidade das notícias mais polêmicas ou caracterizadas como fake news. É o caso do site G1 anteriormente mencionado, o qual não se restringiu ao período eleitoral, mas fez deste setor algo permanente, visando exatamente oferecer ao leitor a possibilidade de saber, constatar a origem da notícia veiculada e assim, a sua autenticidade.

As pessoas, entidades e empresas especializadas ou não na divulgação de notícias,

\footnotetext{
${ }^{6}$ Informação coletada no site:

https://www.correiobraziliense.com.br/app/noticia/tecnologia/2018/03/08/interna_tecnologia,664835/fake-newsse-espalham-70-mais-rapido-que-noticias-verdadeiras.shtml em 15/10/2018 as 23:23.

${ }^{7} \mathrm{https}: / /$ www.bbc.com/portuguese/brasil-45768006 em 15/10/2018 às 23:40.

${ }^{8} \mathrm{https}: / /$ www.correiobraziliense.com.br/app/noticia/tecnologia/2018/03/08/interna_tecnologia,664835/fakenews-se-espalham-70-mais-rapido-que-noticias-verdadeiras.shtml em 15/10/2018 as 24:12.
} 
precisam ter em mente a responsabilidade na disseminação de conteúdo falso, o qual, conforme defendemos, poderá alterar inclusive o resultado de uma campanha presidencial por exemplo. A facilidade no manuseio dos smartphones, tablets e computadores aliada a rapidez de compartilhamento da informação fazem com que, em poucos instantes, possa ser disseminado conteúdo político afastado da realidade e assim, influenciar o voto do cidadão, o que nos leva a analisar o outro efeito causado pela disseminação das fakes news que veremos a seguir.

O advento das redes sociais como antecipado neste texto, não só trouxe a tona a rapidez de disseminação da informação como também a possibilidade de que qualquer cidadão expusesse para um sem número de seguidores suas opiniões, crenças e preconceitos. Isto permitiu que segmentos da sociedade se unissem em torno de determinado tema, permitindo a união de ideologias antes afastadas pela impossibilidade física de conexão, desaparecida com a virtualidade das relações. A virtualização, como bem asseverou Pierre Levy citado por BRITO e LONGHI, 2018: “ implica a irreversibilidade de seus efeitos, de indeterminação em seu processo e de invenção em seu esforço quanto à atualização".

O homem, até então adstrito a um pequeno contingente social apto a apreender suas opiniões, crenças e preconceitos, passou a fazer parte de uma grande rede, a rede mundial de computadores, com capacidade infinita de alcance e, por isto mesmo, com potencial de arregimentar mais seguidores em torno de uma causa.

Neste sentido, as redes sociais e seus algoritmos formam bolhas sociais - e também ideológicas - capazes de influenciar multidões e assim fazer diferença, por exemplo, no resultado de um pleito eleitoral. Desta forma, a disseminação de falsas notícias possuem o efeito de incutir ideologias através da exposição dos usuários a conteúdos não checados ou deliberadamente manipulados, mas que, por estarem inseridos num contexto de bolha social da qual se faz parte, tem o condão de influenciar na conduta dos seus destinatários como se fosse verdade.

Este fenômeno, nem tão recente na história da humanidade que sempre se dividiu em nichos sociais, assumiu relevância específica com o advento das redes sociais, mecanismos capazes de disseminar contéudo de forma célere e simples, se utilizando da emoção, diversão, e porque não dizer da desinformação de seus usuários para prevalecer.

Chegamos ao que se chama da era da pós verdade, termo cunhado na última década e 
que assumiu maior relevância a partir de 2016, quando foi eleita pelo Dicionário Oxford ${ }^{9} \mathrm{a}$ palavra do ano, o que faz todo sentido, explico porque.

A partir do momento em que as pessoas passaram a ter liberdade de acesso às redes sociais, sem qualquer tipo de dificuldade ou censura, passaram a acessar informações de seus interesses, provocando nos algoritmos a disseminação de conteúdos polarizados, contribuindo na formação das já mencionadas bolhas sociais. Estas bolhas sociais possuem a características de agregarem pessoas com a mesma ideologia e assim, cada vez mais distantes do conteúdo ideológico diferente do seu.

Essa polarização tem como efeito a ausência de contraditório ou mais ainda, ausência de consciência crítica, relegando a verdade a um fator secundário, é o que se convencionou chamar pós-verdade, cujo significado remonta à ideia de que vivemos numa época em que a verdade não é fator primordial para construção da informação e até mesmo do pensamento, mas sim o que se acredita que é, independentemente de se constituir um fato objetivo. Segundo D'ANCONA, 2018: "No cerne da tendência global está um desmoronamento do valor da verdade, comparável ao colapso de uma moeda ou de uma ação”.

As chamadas notícias falsas assumem especial importância neste contexto da pós verdade, tendo em vista que, numa época em que a verdade não importa, aquelas notícias, desde que consentâneas com as opiniões, dogmas e crenças da bolha social a que pertence, reforçarão e impulsionarão seus argumentos.

Isto se torna extremamente grave diante do fato de que as relações sociais se basearão não num fundamento comum do que é verdade e, portanto, conceito incontestável, mas sim com base no que a pessoa acha que é certo e portanto, criando a própria realidade, gerando conflitos e situações esdrúxulas como as protagonizadas pelo então candidato à presidência dos Estados Unidos Donald Trump, nas eleições de 2016.

Anda segundo D'ANCONA, 2018: "Essa é a característica da pós-verdade. A questão não é determinar a verdade por meio de um processo de avaliação racional e conclusiva. Você escolhe sua própria realidade, como se escolhesse comida no buffet".

Em se tratando de política e da polarização ideológica generalizada, as notícias falsas foram usadas para causar tumulto e reforçar posicionamentos - ou mesmo, acentuá-los. No caso do Brexit e das eleições americanas, os nervos estavam ainda mais à flor da pele por

\footnotetext{
${ }^{9}<$ https://www.politize.com.br/noticias-falsas-pos-verdade/> Acesso em 02/04/2019 às 23:12.
} 
serem assuntos determinantes ao futuro daqueles países, o que não foi diferente do que aconteceu no Brasil nas eleições presidenciais de 2018.

Chegamos assim ao ponto de verificação de como o advento das redes sociais e seu crescimento popularizou a divulgação de notícias falsas e como estas estiveram presentes nas propagandas eleitorais nos últimos sufrágios.

A informatização e consequentemente crescimento tecnológico pelo qual passamos a partir dos anos 90 fez com que um número maior de pessoas tivesse acesso à rede mundial de computadores e por ato próprio pudessem emitir suas opiniões e pensamentos através das mesmas. Com o advento das eleições majoritárias de 2018, verificou-se um aumento expressivo na quantidade de noticias falsas veiculadas na rede.

A facilidade no compartilhamento das notícias fez com que os usuários, independentemente do seu conteúdo, as divulgassem livre da checagem acerca da sua veracidade, pois contemplariam ideologias similares às do seu emissor, remetendo assim a uma corrente ideológica perigosamente baseada em afirmações não necessariamente verdadeiras, numa alusão ao que já vimos acerca da pós-verdade.

O interessante notar que não há um mínimo de pudor na proliferação das notícias falsas sobretudo em matéria eleitoral, tendo em vista que o objetivo, neste caso específico. não é a informação ou esclarecimento a respeito de um fato, mas sim a divulgação de uma dada ideologia acrítica e baseada em factoides.

Para tanto, a proliferação através das redes tem contribuído e muito para o avanço das chamadas fake news pois dada a rapidez e facilidade com que são compartilhadas, denotam o descompromisso com a checagem na origem e a necessidade cada vez mais frequente em ser parte de um processo de descredenciamento da figura pública, no caso das eleições, do adversário político, tendo em vista que a corrida pelo voto abre alas para um verdadeiro "vale tudo".

As eleições são períodos em que a busca pelo voto se caracteriza pela proliferação da propaganda eleitoral, oportunidade que os candidatos têm para expor suas propostas de campanha assim como utilizam-na, usualmente, como forma de apontar os "erros" do candidato adversário. Acontece que isto não é feito de forma honesta e verossímil, pelo contrário, quando o objetivo é desqualificar o candidato ou sua ideologia, vale lançar mão de notícias que deturpem o conteúdo da proposta alheia e não digam respeito necessariamente ao 
programa partidário, pendendo para notícias de cunho pessoal e aleatório.

Aliás, vale aqui definir o que seja a propaganda de modo geral, sem a qualificadora do eleitoral, o que segundo BRITO, 2014, seria uma estratégia para influenciar o seu destinatário, através da divulgação de informações na mídia, de forma a familiarizá-lo com o seu conteúdo ou produto, promovendo assim a sua identificação e assim, a sua preferência para contratá-lo ou adquiri-lo conforme o caso.

No que tange à propaganda eleitoral, nos dizeres de Marcos Ramayama citado por BRITO, 2014, pág. 105: “...espécie de propaganda que tem a finalidade precípua de divulgar ideias e propagandas dos candidatos. É a oportunidade que a legislação eleitoral atribui ao candidato para exteriorizar o símbolo real do mandato representativo e partidário." A propaganda pode-se dizer, é uma forma de se difundir ideologia.

A propaganda eleitoral como forma de trazer a público as ideias, planos de governo e propostas dos candidatos às eleições, trazem em si alta carga de conteúdo ideológico, de forma que vem regulamentada na legislação eleitoral desde os seus primórdios, com o Código Eleitoral de 1963 em que pese sob a rubrica "propaganda partidária" e através das sucessivas leis e resoluções que regulamentam as eleições.

Trata-se, portanto, de eficiente mecanismo de marketing, cuja proposta é influenciar seus destinatários de forma que através do recurso da propaganda queiram: comprar o produto, ter o serviço oferecido ou, no caso das eleições, escolhido determinado candidato. Não é à toa que alta quantia de recursos são gastas objetivando investir neste mister. Nesse sentido, sobre o papel da publicidade em tempos de pós-modernidade, diz LIPOVETSKY citado por PRATES, 2018:

“Com a morte do discurso de autoridade, a afirmação de um parâmetro tornou-se um jogo em que sedução, publicidade e marketing desempenham papéis fundamentais, mas em constante movimento. Ou seja, nada é intocável ou perene. A posteridade 'e como o horizonte, uma linha que se afasta à medida em que o indivíduo se aproxima. Se existe, parece um mistério. Não se pode estipular os critérios de acesso a ela. Como a moda, tudo é passageiro."

Nesse sentido, em decorrência da virtualização promovida com o advento da Sociedade da informação, essa forma de divulgação das propostas dos candidatos sofreu profundas alterações a respeito da maneira como vem sendo feita, sobretudo com o advento 
das redes sociais. A propaganda impressa e analógica, naturalmente, deu lugar à propaganda virtual e com isso, conferiu maior alcance e celeridade à mesma. Diante desta constatação, resta-nos a seguinte indagação: a divulgação de conteúdo inverídico teria aumentado com esta nova forma de comunicação digital? A resposta positiva se impõe.

É que, se antes a propaganda eleitoral tinha um alcance menor dada a limitação espacial e gráfica, hoje logicamente, por força da facilidade promovida com a rede mundial de computadores, tornou-se mais fácil o compartilhamento das informações e consequentemente a probabilidade de divulgação de conteúdos inverídicos, fato este agravado pela possibilidade de que cada usuário, individualmente, realize uma postagem sem qualquer tipo de filtro.

A disseminação das fake news em tempo de propaganda eleitoral é algo que se tornou recorrente e ficou patente sobretudo nas eleições presidenciais americanas de 2016 e posteriormente aqui no Brasil, nas eleições presidenciais de 2018. Em ambos os casos, foi notório o número de informações falsas e até mesmo bizarras, visando alterar as intenções de voto dos eleitores e indiretamente, incutir a ideologia do candidato cuja vitória se pretendia.

No caso das eleições presidenciais americanas o próprio candidato e atual presidente Donald Trump adotou o discurso da pós-verdade, em que o que o importante não é a verdade, mas o impacto causado. Segundo D'ANCONA (2018, p 25), em sua campanha de 2016, ao invés de alimentar o eleitorado com informações a respeito de sua carreira ou detalhes sobre seu currículo, preferiu um discurso baseado na desagregação, oferecendo ao eleitorado um "inimigo" contra quem eles poderiam se unir, recheando esse discurso com informações falsas que quando questionadas eram tidas como interpretação a respeito dos fatos.

O referido político entendeu que o poder da disseminação do seu discurso, floreado com informações não verossímeis, tinham o poder de agregar pessoas que pensavam como ele, ou, não tinham interesse suficiente em checar as informações que eram por ele mesmo ou seus prepostos espalhadas no mundo virtual, de forma que pouco a pouco foi ganhando a simpatia e aumentando seu eleitorado.

Ainda sobre esta temática, verificou-se que, dado a alta carga de litigiosidade que se instalou entre os opositores naquele país, eram cada vez mais necessárias infirmações que viessem a depor contra o candidato adversário, de modo a denegrir a sua imagem e reforçar a ideologia partidária de Donald Trump que, sabiamente, soube usar a mídia a seu favor. Considerando nesse contexto de pós-verdade que os fatos passaram a não ter a mesma 
relevância que antigamente, posto que o que tem valia é o discurso baseado na emoção e a ideologia que se quer incutir, conclui-se que ao cidadão, cabe a escolha a respeito da versão que pretende adotar para decidir em quem votar, seja ideologicamente, seja pesquisando a respeito da veracidade das informações que chegam ao seu conhecimento.

O aumento das fake news e sua incorporação no mundo político através da propaganda eleitoral iniciou-se assim, em virtude de sua utilização enquanto ferramenta de discurso ideológico e arrebatador, numa era de informação em rede, célere onde o eleitorado não está preocupado com verdade dos fatos, mas sim com o reforço ideológico que ela pode trazer. Resumiu perfeitamente D'ANCONA, 2018 em sua obra p. 38: “O que é novo é a extensão pela qual, no novo cenário de digitalização e interconexão global, a emoção está recuperando sua primazia e a verdade, batendo em retirada".

Em entrevista à Folha de São Paulo em 19.02.2017 ${ }^{10}$, o historiador professor emérito da Universidade de Harvard Robert Darnton, mencionou que as fake news não são um fenômeno recente como se poderia achar, ou que estivessem vinculadas ao nascimento da chamada Sociedade da informação e o advento das redes sociais, mas já existiam desde Idade Antiga, dando exemplo de como Cartas injuriosas poderiam hoje ser consideradas fake news. Segundo o mesmo historiador, sem fake news, redes sociais e novas mídias, Trump não teria sido eleito.

As eleições presidenciais americanas são o exemplo clássico de como as informações manipuladas ou deliberadamente inverídicas, possuem o condão de aliciar mentes, ampliando as chamadas bolhas ideológicas anteriormente mencionadas, a ponto de promover (ou impulsionar para usar um termo mais moderno) uma candidatura e desestabilizar a do seu adversário.

Segundo site do Estadão ${ }^{11}$ :

“As eleições americanas do ano passado foram um exemplo para o mundo sobre a influência de conteúdo enganoso sobre o voto. $\mathrm{O}$ compartilhamento de fake news e de textos extremistas,

\footnotetext{
${ }^{10}<$ https://www1.folha.uol.com.br/ilustrissima/2017/02/1859726-noticias-falsas-existem-desde-o-seculo-6afirma-historiador-robert-darnton.shtml. > Acesso em 13.04.19 as 00:00.

${ }^{11}<$ http://infograficos.estadao.com.br/focas/politico-em-construcao/materia/fake-news-devem-causar-impactoem-eleicoes-de-2018> Acesso em 13 de abril de 2019 as 00:54.
} 
sensacionalistas, conspiratórios e de opinião disfarçados de notícias jornalísticas ganhou força frente a reportagens escritas por profissionais. Um levantamento do Projeto de Propaganda Computacional da Universidade de Oxford analisou os compartilhamentos feitos por usuários do Twitter no estado de Michigan durante o período eleitoral. Os pesquisadores descobriram que $46,5 \%$ de todo o conteúdo apresentado como noticioso sobre política era composto por notícias falsas, documentos não verificados do WikiLeaks e matérias de origem russa. Recentemente, descobriu-se que 126 milhões de internautas dos EUA no Facebook foram expostos ao conteúdo produzido na Rússia sobre a eleição americana."

Importante ressaltar que o advento e popularização da tecnologia, facilitou a promoção de conteúdo por qualquer pessoa, o que também incrementou a indústria das notícias falsas, pois basta ter acesso a internet ou qualquer rede social, para que se possa produzir conteúdo sem a devida certificação acerca de sua veracidade.

No caso do Brasil, tivemos uma repetição do que aconteceu nas eleições americanas de 2016, pois o advento da informatização já era uma realidade e o acesso às informações acontece de maneira muito mais fácil, por qualquer pessoa do povo, a qual pode inserir conteúdo na rede a partir até mesmo de um celular. Assim, os conteúdos postados variavam de informações verdadeiras a fake news, estas últimas com alto poder de compartilhamento.

No site da BBC News Brasil em Londres ${ }^{12}$ apurou-se que a rede Whatsapp é a mais difundida entre eleitores brasileiros, utilizada por 66\% deles, ou 97 milhões de pessoas, segundo a pesquisa Datafolha divulgada na época das eleições. Chega a ser maior do que o Facebook, usado por $58 \%$ dos brasileiros que votam. Ou seja, o poder de alcance das mídias sociais, dado o grande número de seguidores acessos e compartilhamentos, pode promover a alteração das intenções de voto da parcela da população que está indecisa e assim alterar o resultado das eleições.

Instaurou-se, com a utilização destes instrumentos no âmbito eleitoral, uma verdadeira "guerra" nas redes, polarizando as candidaturas e caracterizando-se pelo envio de mensagens até mesmo contraditórias, havendo o questionamento a respeito de até onde

\footnotetext{
${ }^{12}<$ https://www.bbc.com/portuguese/brasil-45666742 > Acesso em 13.04.2019.
} 
haveria liberdade de expressão do indivíduo em postar conteúdo sabidamente falso no intuito de influenciar o convencimento do eleitor. A indicação adotada pelos Tribunais Superiores e pela doutrina sobre o tema como já dito acima, é no sentido de que, sendo a internet um veículo de informação democrático e gratuito a proibição de livre manifestação deve ser algo excepcional.

\section{CONSIDERAÇÕES FINAIS}

Por tudo que se viu no texto, havendo preponderância do meio virtual como mecanismo de divulgação da propaganda eleitoral, o número de notícias falsas aumentou consideravelmente, posto que impossível a checagem da sua origem diante da celeridade do compartilhamento da informação e anonimato, característicos da rede social. Entretanto, apesar das políticas dos provedores em impedir o avanço deste tipo de notícia, através da colocação de filtros, fato é que são bastante consumidas, o que denota a preferência do público neste tema.

Convém ressaltar que o aumento das fake news e sua incorporação no mundo político através da propaganda eleitoral desenvolveu-se no campo virtual, em virtude de sua utilização enquanto ferramenta de discurso ideológico e arrebatador, numa era de informação em rede, célere em que o eleitorado não está, necessariamente, preocupado com' a verdade dos fatos, mas sim com o reforço ideológico que ela pode trazer.

Isto posto, conclui-se que há sim a possibilidade de as chamadas notícias falsas influenciarem no resultado do pleito, considerando a polarização das opções políticas e o grande número de indecisos na última eleição, razão que chama atenção para o fato de que os mecanismos de monitoramento da propaganda eleitoral em rede devem estar presentes para que não haja manipulação ou ocorrência de ilícitos.

\section{REFERÊNCIAS}

BUCCI. Daniela. Direito Eleitoral e Liberdade de Expressão. Limites Materiais. São Paulo: Almedina. 2018.

BRITO. Auriney e outro. Propaganda Eleitoral na Internet. São Paulo: Saraiva. 2014. 
D'ANCONA. Matthew. Pós Verdade. A nova Guerra contra os fatos em tempos de fake news. Barueri: Faro Editorial. 2018.

CASTELLS, Manuel. Redes de indignação e esperança. Rio de Janeiro: Zahar, 2013.

RAIS. Diogo, MENEGUETTI. Pamela e Outros. Direito Eleitoral Digital. São Paulo: Revista dos Tribunais. 2018.

MASSUDA. Yoneji. A Sociedade da Informação como Sociedade Pós-industrial. Rio de Janeiro: Rio, 1982. p. 35

PRATES. Cristina Cantú. Publicidade na Internet. Consequências jurídicas. Curitiba: Juruá. 2015.

SAMPAIO. José Adércio Leite. Teoria da Constituição e dos Direitos Fundamentais. Belo Horizonte: Del Rey. 2013.

TAVARES, André Ramos. Curso de Direito Constitucional. São Paulo: Saraiva. 2003.

<https://www.bbc.com/portuguese/brasil-45666742 > Acesso em 13 de abril de 2019.

<https://www.correiobraziliense.com.br/app/noticia/tecnologia/2018/03/08/interna_tecnologia ,664835/fake-news-se-espalham-70-mais-rapido-que-noticias-verdadeiras.shtml > Acesso em 13 de abril de 2019.

<http://infograficos.estadao.com.br/focas/politico-em-construcao/materia/fake-news-devemcausar-impacto-em-eleicoes-de-2018> Acesso em 13 de abril de 2019.

<https://www.politize.com.br/noticias-falsas-pos-verdade/> Acesso em 13 de abril de 2019.

<https://www1.folha.uol.com.br/ilustrissima/2017/02/1859726-noticias-falsas-existem-desdeo-seculo-6-afirma-historiador-robert-darnton.shtml> Acesso em 13 de abril de 2019. 